THE INTERNATIONAL

REVIEW OF RESEARCH IN

OPEN AND DISTANCE LEARNING

\title{
Designing for Learning: Online Social Networks as a Classroom Environment
}
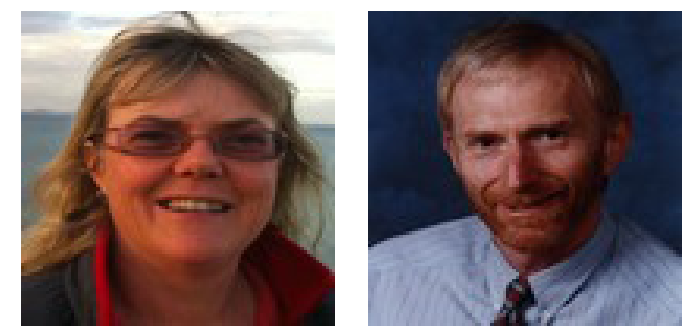

Gail Casey and Terry Evans

Deakin University, Australia

\section{Abstract}

This paper deploys notions of emergence, connections, and designs for learning to conceptualize high school students' interactions when using online social media as a learning environment. It makes links to chaos and complexity theories and to fractal patterns as it reports on a part of the first author's action research study, conducted while she was a teacher working in an Australian public high school and completing her PhD. The study investigates the use of a Ning online social network as a learning environment shared by seven classes, and it examines students' reactions and online activity while using a range of social media and Web 2.0 tools.

The authors use Graham Nuthall's (2007) "lens on learning” to explore the social processes and culture of this shared online classroom. The paper uses his extensive body of research and analyses of classroom learning processes to conceptualize and analyze data throughout the action research cycle. It discusses the pedagogical implications that arise from the use of social media and, in so doing, challenges traditional models of teaching and learning.

Keywords: Social networking; online learning; student learning; emergence; chaos and complexity

\section{Introduction}

Modern school systems place increasingly sophisticated pedagogical demands on teachers, including the need to be able to make decisions about how, when, and with whom they should select and use new technologies in their teaching. Many of these new demands also, at times, conflict with the traditions of what it means to teach and learn. When used effectively, new technologies have the potential to allow students to "speak" to a world far beyond their local community. In doing so, they empower students to write and publish for 
a global audience, encouraging them to be more than just the audience (Wells, 2007). Research exploring the impact that new information and communication technologies (ICTs) are having on teaching and the ways students learn, particularly the role of one-to-one laptops in the classroom, continues to be a priority for many educational policymakers. And due to young people's attraction to them, social networks are emerging as an important tool in today's schools. Senior high school students are interacting in such networks with or without their teachers' consent (and, at times, without their knowledge) through study groups organized using Facebook (http://www.facebook.com/). In Years 7 to 10 of the Australian school system, a small number of teachers are exploring the use of private social networks, such as Nings (http://www.ning.com/), while some primary (elementary) school teachers explore environments set up specifically for education, such as SuperClubsPLUS (http://www.scplus.com/d/index.php). Connections, emergence, chaos, complexity, and fractals are theories that the authors will discuss at length throughout this paper as they share the sometimes unexpected outcomes of this classroom action research study. These theories have helped the authors appreciate learning as a dynamic and shared experience that extends beyond the boundaries of the classroom, where the unpredictable is considered a treasured learning experience. They allowed the teacher to relax her hold on the teacher "power" in the classroom and gave her the confidence to design new learning experiences that challenged what it meant to teach and learn.

Many researchers have asked questions about today's youth, who are growing up in a digital world, and about the Web as a transformative medium (Brown, 2002; Prensky, 2010; Reamsbottom \& Toth, 2008; Sultan, 2010; Weinberger, 2008; Wheeler, 2001; Williams, 2008; Yuen \& Yuen, 2008). Consequently, exploration of and discussion about the connections between young people, social networks, and education is needed. There is also a pressing need for students to be literate in the new digital practices that are required to actively participate in the global economy. Such views are commonly expressed by Dillon (2006), Johnson and Kress (2003), Edmonds (2006), Luke and Elkins (2002), and Merchant (2007). A major concern many educators have is the fact that students often communicate among themselves in ways that school systems do not formally recognize but that the workplace is moving to embrace. An example of this can be seen at the web page of Geelong City Council (http://www.geelongaustralia.com.au/Default.aspx), which uses both Facebook and Twitter to advertise and promote local events. Worldwide acceptance of social networking in the workplace is paving the way for education to take advantage of this type of connected learning.

The Internet, social media, and Web 2.0 are becoming important components of students' education as schools increasingly provide a laptop or other portable device to each student, but just how these new ICTs should be used is still a topic of debate. School administrators, generally, are wary of social media in the classroom. Students using online social media in school settings or elsewhere have access to content every hour of every day, but teachers are unable to constantly monitor them; hence, an element of understanding and trust is required. Social media platforms enable students to develop content and interact with one another and allow them to build a sense of community. Furthermore engaging with social 
media becomes addictive for certain young people as they constantly monitor their own developed online presence for new activity or comment. Mason (2008, p. 70), however, describes some positive qualities of social media use in the classroom: They require students to participate, think, contribute, and become active in their learning. Using a social network such as a Ning in the classroom allows the teacher not only to incorporate multimedia and multimodal texts but also to share these quickly and easily, providing a collaborative learning environment where students can communicate at any time. This new reality has the potential to significantly impact how we design learning experiences if we take advantage of opportunities for connectivity. By incorporating social media into the lives of students in the classroom, teachers also incorporate the new literacies that are becoming part of students' out-of-school lives (Alvarez, 2001; Fletcher, 2007; Glover \& Oliver, 2008; Hahn, 2008).

Graham Nuthall's approach to learning underpins the analysis of the research reported in this article. By his own account, Nuthall was drawn to social constructivist theory, although he was relatively pessimistic about the feasibility of social constructivist approaches to teaching, except in rather narrowly specified situations (Brophy, 2006). Nuthall (2007, p. 14) believed that teaching is about sensitivity, adaptation, and adjusting to the "here-andnow" circumstances of particular students. He believed that it is about making immediate and intuitive decisions as a lesson or activity progresses: Topics that interest some students do not interest others, and solutions that work one day may not the next. Nuthall makes it clear that students learn a great deal from their peers. In fact, their motivations, interests, attention, and involvement may all be strongly affected by relationships with their peers. By looking at the interactions between students in this study, patterns become visible and can be extrapolated. Simple conversations between students have resulted in important classroom decisions being made. New and emergent knowledge is the end point of both the informal and the formal learning that occurred.

In traditional schooling, teaching tends to imply that the content is a finished and complete packet of information to be "transferred" from teacher to learner, and this notion is directly or tacitly conveyed to students (Doll, 2005a, p. 175). In this simplistic transfer approach, Doll argues that the complex "poetry" of learning goes ignored or unrecognized. This article attempts to provide examples of such poetry with its discussions on the interactions and learning experiences of the students. It reports on the way they presented their ideas, reacted to their peer's ideas, and how the complex patterns of communication arose against the backdrop of their own experiences. These patterns made links between connections and emergence and had a significant impact on the design and implementation of the teaching and learning process throughout the study.

\section{Research Design}

This action research investigates the use of online social media as a learning environment for adolescents between 13 and 16 years old throughout semester 2, 2010. The first author (Casey) is both teacher and doctoral researcher (hereafter referred to as the research- 
er), and the second author (Evans) is the doctoral supervisor. The project involved all of Casey's classes at a Year 7 to 12 coeducational public high school with a student population of approximately 90o. The school is located in Geelong, a city with a population of approximately 200,000 located about 80 kilometers from the Victorian state capital of Melbourne in Australia. Students are predominantly from a mid-range of socioeconomic backgrounds. The school runs a vertical curriculum using A, B, C, and D as subject levels (A being the lowest) in Years 8 to 10, where students of different year levels are often in the same class. All vertical classes operate for five periods per week, each being approximately 50 minutes. The researcher taught seven classes with an average-size class of 25 students comprising

- four Year 7 Information Technology classes (2 periods per week for each class);

- one level B Mathematics class (5 periods per week);

- one level B Information Technology class (5 periods per week); and

- one level C Multimedia class (5 periods per week).

The study searched for new approaches to learning. It took place during the school's initial stages of their one-to-one laptop program when all Year 7 students were required to lease a small laptop from the school. Throughout the research, online tools and environments were used in all of the researcher's classes to deliver the classroom curriculum. One main Ning social network was used as a base camp to communicate, publish, and link to other online environments. The teacher covered the curriculum topics required within each relevant subject area. But with all her classes she had the freedom to decide how the content was delivered. The researcher incorporated a range of online tools and environments into the content delivery, presentation, communication, and publication of class and student work.

All the students used pseudonyms when working online and were able to change these, their online profiles, and avatars at any time; hence, they were not openly identifiable to one another. Typically more than one class worked on the same online project at the same time, and usually the four Year 7 classes worked on the same project at the same time.

The researcher focused on three areas.

1. Teacher: What new demands does this type of classroom practice bring to the teacher?

2. Student: What scaffolding is needed to help students cope with the complexities of such an environment?

3. Learning: What potential does this type of online social medium have for learning?

This article will focus on the second area, that of the student. Figure 1 shows the main concepts of this focus area. 


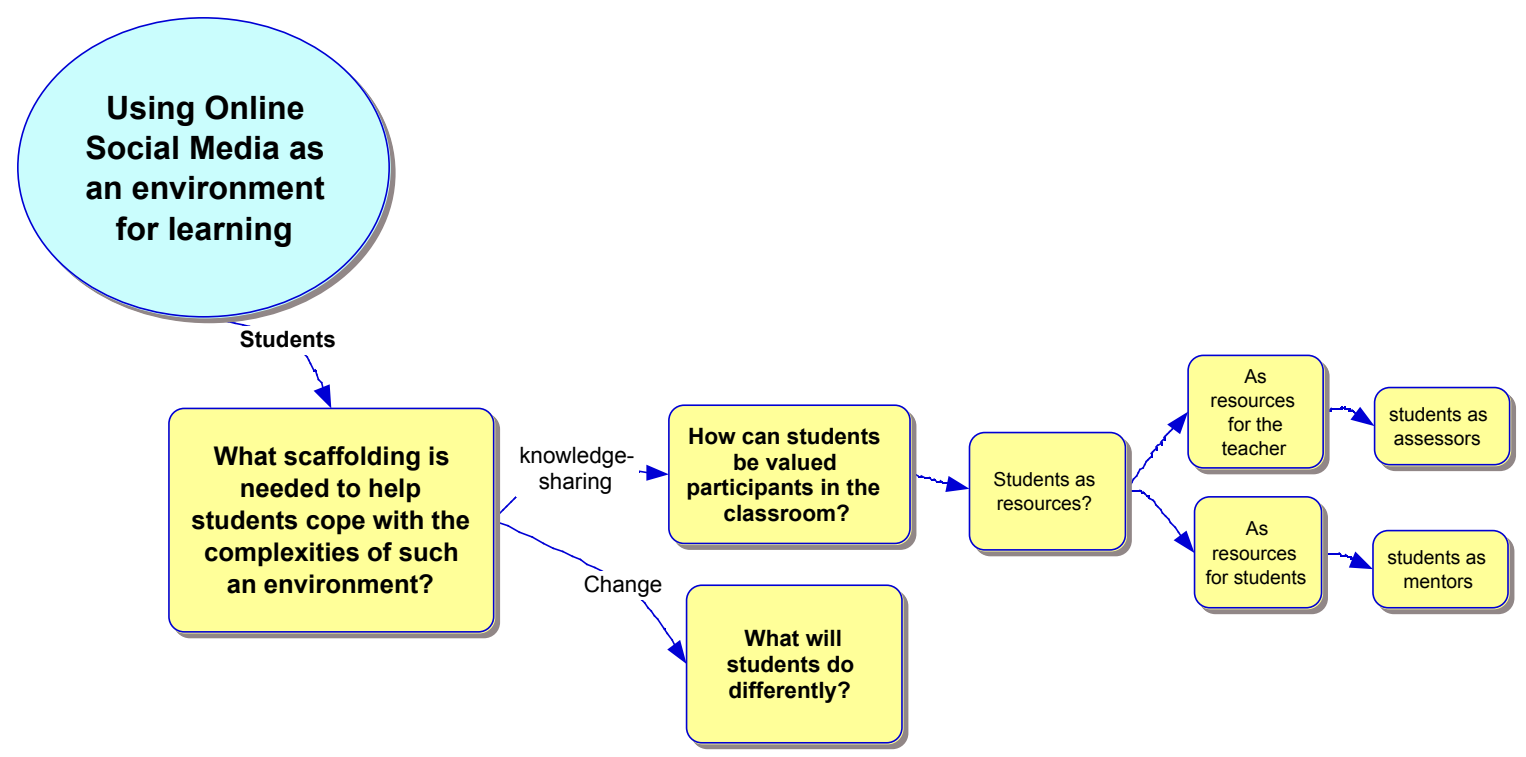

Figure 1. The focus of the research-students valued as resources for both their peers and their teacher.

This study used Armstrong and Moore's framework (2004, p. 13) of the action research cycle that explicitly encourages inclusive processes through the research design, practice and process, and outcomes. This framework does not suggest a sequence of segmented activities. Rather, it encourages a continuous, overlapping process of reflection, consultation, planning, and change. The researcher found this action research framework flexible enough to use throughout the data collection, which was important due to the many classroom projects and multiple classes involved: There could be as many as six classes, totalling approximately 150 students, at different year levels and stages working on the same project, including cross-class interaction. Thus, any stage of the action research cycle could become extended and might overlap with others. However, the processes of observing, identifying issues, raising questions, developing ideas, monitoring, evaluating, and changing what and how things were done were constant and became part of teaching life. These processes provided the researcher with ideas and inspiration on how to set about changing places, practices, and minds, as encouraged by Armstrong and Moore (2004, p. 14). The framework supported the flexibility that was needed in the curriculum delivery and allowed the researcher to think through other models of delivery, which assisted in helping her move away from the "instructional order" of the traditional classroom.

In order to develop authentic teaching and learning experiences which addressed the focus areas, the researcher chose to work full-time at the research site, ensuring that the pressures of full-time teaching could be related authentically in the research design. Hence, the researcher had a full allocation of teaching and other obligations, which included yard duty and scheduled meetings, although she took a leave of absence for approximately one week twice each term, or as required, to support the documentation and analysis of the research cycle. 
Data collected included

- teacher planning documents, which incorporated teacher-directed activities, thoughts for future development of projects, resources, and general ideas for integrating Web 2.o into projects and helping students become more independent learners;

- the teacher's field notes, taken while in the classroom and reflections made soon after each class was concluded;

- end-of-week teacher reflections, along with big picture planning and reflections at the end of each five-week period;

- student work, which included screen clips from online Ning activity and scans of handwritten student self-evaluations and reflections; and

- $\quad$ summary notes from teacher critical friend discussions.

This study used social networking as an environment for teaching and learning in a way that, at times, challenged what it means to teach and learn. The analysis of the data thus needed to be sensitive to emergent ideas. This analysis was based on identifying what was useful for educators or not, rather than on what was "right" or "wrong." Szempli and Stupnicka (2003, p. 1) explain that when we observe the evolution of various phenomena in the macroscopic world that surrounds us, we often use the terms chaos or chaotic, meaning that the changes in time are without pattern or control and hence are unpredictable and uncontrollable. Just as long-term weather forecasting is used as an example when conceptualizing chaotic behavior, due to the great array of influencing factors (such as temperature, barometric pressure, wind direction, and precipitation), one could argue that working with adolescents in the classroom produces a similarly large array of influencing factors that lead to "storms" or "calms" of a different kind. Chaos and complexity are perspectives in new science and postmodern inquiry that may implicate significant changes in how we understand and approach curriculum (Fleener, 2005).The data from this study provide insight into how a teacher might conceptualize chaos and complexity in the classroom and thus foster the development of activities that support emergent and connected learning.

A discussion of selected findings and their analyses follows. It uses qualitative data and explores students' online interactions with one another and the classroom teacher while drawing on related theory for analytical discussion.

\section{Designing Learning Experiences}

More than 150 students from the researcher's classes were registered on the Ning during this semester-long study. Members formed 77 groups by the end of the semester on this one network. The Ning offered students a great range of opportunities to form their own groups and discussion forums and become involved in those made by others. Students were able to be explorers, designers, and publishers, and this encouraged them to support their peers, self-reflect, and provide both peer-assessment and self-assessment. The Ning provided stu- 
dents with a "life-like" curriculum (Beane 2006, p. 10) and continued to move away from the "instructional order" of the traditional classroom as the semester progressed. Students supported one another when solving problems and were able to draw upon the relevant, integrated knowledge and skills that many had honed outside the classroom. They were developing what Beane (2006, p. 10) calls self and social meaning. The way students communicated on the Ning allowed them a great deal of flexibility to read and write comments and to ask questions and seek clarification. They also enjoyed the freedom to develop new profiles, change their avatars, make friend requests, and send "gifts."

Students became active users of the Ning, and a complex, self-organizing interactive environment appeared to evolve. Teaching and learning was occurring, it seemed, as much informally as formally. Figure 2 shows a screen clip from the main page of the Ning online learning environment used throughout this research. (Note that group membership numbers shown do not indicate the number of students accessing a particular group but rather are the number who chose to formally join and hence are able to leave comments and upload to that group. The actual number of students viewing and using information from different groups is often a significantly larger number than the membership number indicates.)

\section{GHS 2010}

\section{Social Networking - Learning to Learn}

\section{Main My Page Members Groups Polls Apps Photos Videos Blogs Forum My Network}

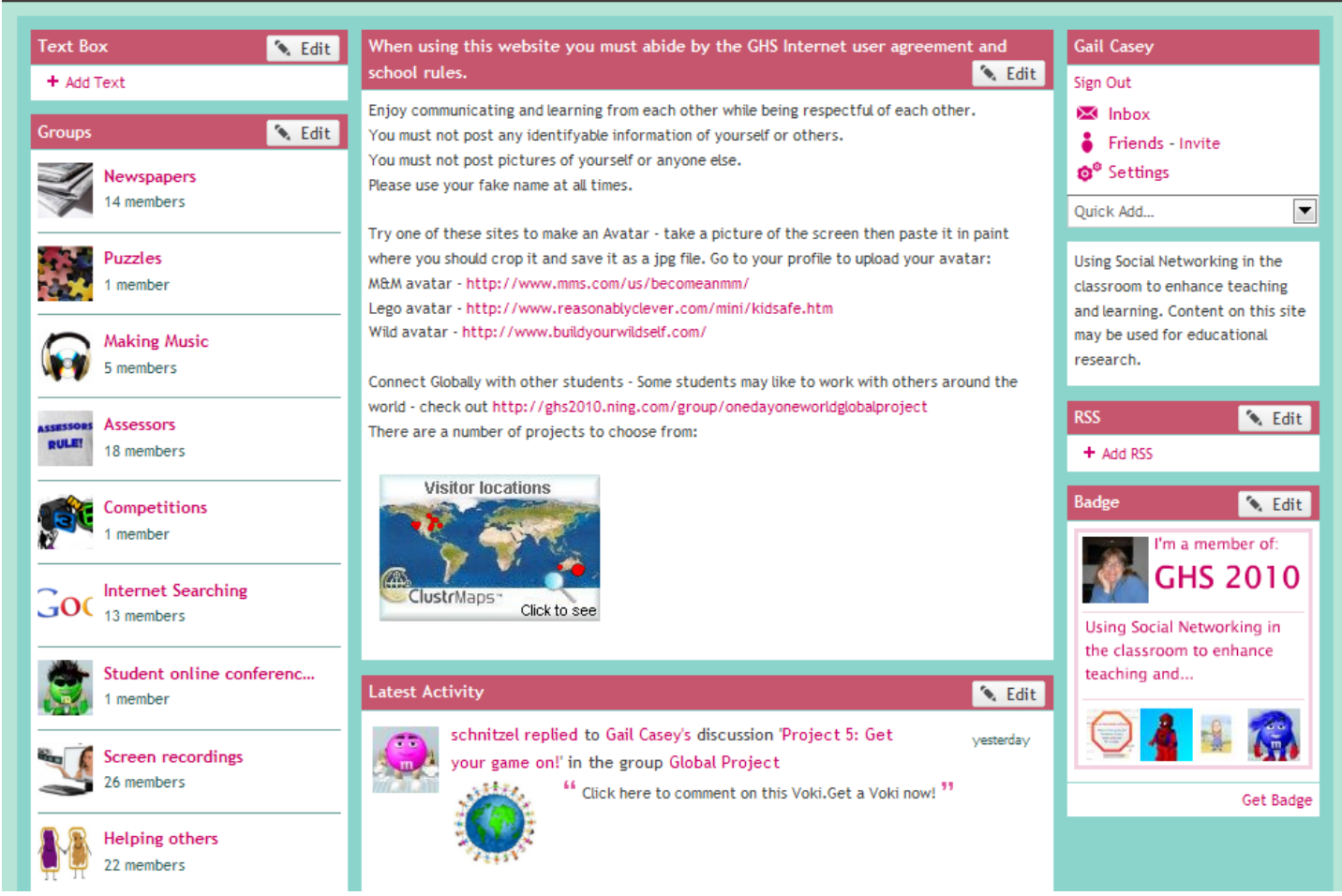

Figure 2. Screen clip of the Ning social networking site with 159 members from the teacher's classes. 
A large volume of qualitative data was collected throughout the classroom projects. At times there were 75 students in one group publishing their work, so as many as 75 discussion forums could occur in that group. Students found it helpful when their peers posted work because it allowed them to more clearly see, and hence understand, the project expectations. Initially, the traditional concepts of cheating were a topic of conversation, but students eventually perceived that the project design ensured that cheating was not an issue, and they valued learning from one another, which even led to high levels of sophisticated work. As the semester progressed, students were given more opportunities to make decisions and have more responsibility for things such as assessment and feedback to others. Normally, students come into the classroom and expect the teacher to be responsible for assessment; therefore, it took time for some students to accept these new practices, but eventually they did. It was interesting to see that many students were very accepting of the approach and appreciated the extra flexibility. As students provided constructive feedback to one another about important concepts such as assessment, this opened the door to generating new knowledge. In the traditional classroom, it is often the teacher who is the sole viewer and critic of student work. Students started to value the opinions of their peers and, at times, were very critical of peer work that contained little thought or effort or was simply cut-and-pasted from the Internet.

For each of the seven face-to-face classes, the most vocal students rarely participated in online situations. However, three of the quietest students who never appeared to do anything wrong in the classroom were suspended from the Ning or had to be spoken to about their inappropriate behavior, which produced a surprising result. Over the last 10 years in the public school system, it has become rare in the researcher's experience for students to seek assistance outside the classroom without being specifically instructed to do so. However, the students who were banned from the Ning often did want clarification on why they were suspended and directions on what to do to resolve the issue promptly. Students also sent a number of emails to the teacher requesting support to resolve issues. The connections students made through the Ning social network emphasized connectivism, where interactions that were generated by these connections, whether informal or formal, allowed students to behave in different ways and learn from one another rather than just from the teacher. As a result, opportunities to present new and emergent knowledge continued to develop which helped to enhance the teaching and learning process.

The researcher's interpretation of learning and teaching was informed by Nuthall's (2007, p. 36) criteria for effective teaching. His four premises follow, and under each one the researcher discusses how it relates to her research.

- First premise: Students learn what they do, and what they are learning is what you see them doing: writing notes, coping with the boredom without complaining, and later, memorizing headings and details they only partially understand. What they do in the classroom, day after day, is what they become experts at.

Response: After two weeks of using the Ning, most students became competent in the collaborative methods of learning as provided by the social network. There were usually one or 
two students in each class who found the Ning difficult to use and navigate, and these individuals required more support. But by the end of the semester, most students were experts in their new learning environment.

- Second premise: Social relationships determine learning. It's very important to remember that much of what students do in the classroom is determined by their social relationships. Even in the teacher's own territory, the classroom, the student's primary audience is his or her peers. More communication goes on within the peer culture than within the school and classroom culture.

Response: More than 44 student-directed groups were produced in the Ning, where a range of informal learning could be found; some of this is evident in Figure 3.

- Third premise: Effective activities are built around big questions. If we want to design effective learning activities, we must carefully monitor what students are gaining as they engage in focused learning. We have to spend a considerable amount of time and resources monitoring what they are understanding and learning as well as designing and carrying out these activities. Taking the time and providing the resources needed to design effective learning activities means covering much less of the formal curriculum. To justify doing this, we must make sure that the outcomes of these learning activities are significant not only in the official curriculum but also in the lives and interests of the students.

Response: While the researcher valued all aspects of this premise, extra time was not available for activities due to school timetable constraints, but she integrated an approach where students could choose from a range of themes or devise their own.

- Fourth premise: effective activities are managed by the students themselves. The ideal learning activity, in line with the previous three premises, has the following characteristics:

- It focuses on the solution of a major question or problem that is significant in both the discipline and the lives and culture of the students;

- It engages the students continuously in intellectual work that is appropriate in the discipline;

- It provides teachers with opportunities, as the class engages in solving the smaller problems, to monitor individual students' evolving understanding of the content and procedures.

Response: A number of projects the teacher gave to students involved teaching their peers or younger students.

There is more to teaching than simply engaging students in activities, and a good teacher, whether following a traditional model or otherwise, has certain qualities and attributes. 
Atkinson and Claxton (2000, p. 1) argue it is self-evident that much of what teachers (and others) do in the heat of the moment is not premeditated, but intuitive. A situation arises, the teacher responds, and only later (if at all) will she pause to figure out what was going on and why she responded in that manner. Atkinson and Claxton go on to discuss the relationship between the rational and the intuitive, between the explicit and the tacit, and between articulated comprehension and gut feeling. Their discussion of what professionals do and how they learn to do it helped the researcher understand why she often went into the classroom and changed aspects of what lessons she had planned for a given day. She now understands the importance of the role of intuition in professional practice, particularly the significant part it played in her position as a teacher designing projects for learning within this online environment. She kept the words of Draut (2000, p. 267) in mind; he claims that teachers remain accountable for the learners' long-term progress, motivation, and well-being, the focus of many evaluations of practice. This does not change whether an instructor uses a traditional model for teaching and learning or not. In many professions, expert judgment, one variety of intuition, is often wholly or largely intuitive, and a teacher coming to a decision draws upon a vast database of largely inarticulate impressions (as well as documented materials) and may be forced to neglect rich nonverbal, nonmeasurable information if forced to justify every judgment explicitly (Claxton, 2000, p. 37). Yes, the researcher is challenging what it means to teach and learn in this study, but it should remain clear that as the content, delivery, and even assessment methods change in the exploration of connections, emergence, and design for learning, the teacher remains accountable.

\section{Emergence: Social Media as a Classroom Environment}

The analysis of students' online participation and interactions showed that there was a variety of levels for each. Some students took much longer than others to become familiar and comfortable with the Ning environment; these students often preferred "lurking" rather than actively participating. Others openly used the environment to promote their own ideas and interests, increase their own popularity, or present themselves as knowledgeable. Some students also used the Ning to air their frustrations and feelings. The following three examples indicate some emerging patterns of interaction found in the data.

\section{Example 1.}

Throughout the data collection, students were free to make their own groups or to join and communicate with any group on the Ning (except, rarely, when students chose to make a private group). By the end of data collection for this stage, more than 40 out of 77 of these Ning groups were student-directed (that is, they had nothing to do with class projects or teacher instructions). Some of these are shown in Figure 3 below and include "Fortress B," "King of All Groups," "Not enough chairs in a class room," "TF141," "Melbourne Victory," "PC gaming," "Ducks are awesome," "iTunes," "Apple," "Xbox 360's are better then PS3's" and "mr.bean awsomee." Many students, both male and female, enjoyed the connectedness provided by these student-directed groups. This connectedness is described well by Pickover (1996, p. 4). In his book Fractal Horizon, he described watching the surf break and considering the billions of water particles responding separately to the conflicts between 
gravity, wind, inertia, and cohesion. One could make an analogy to this surf breaking if one imagines each student as a water droplet. Each droplet is measuring its own local forces from moment to moment and calculating its own path through the chaos. The result is a thing of beauty. Students formed groups, with each individual having the opportunity to add, join, contribute, or lurk. The decision to do any of these things changed depending on how a student felt at any given time and how they wanted to respond to their peers. The result was a massive bank of student-documented interests and thinking. Many times the researcher pondered, without success, how one could use this "thing of beauty" in the formal arena of learning, rather than watching it dissipate, just as the surf.

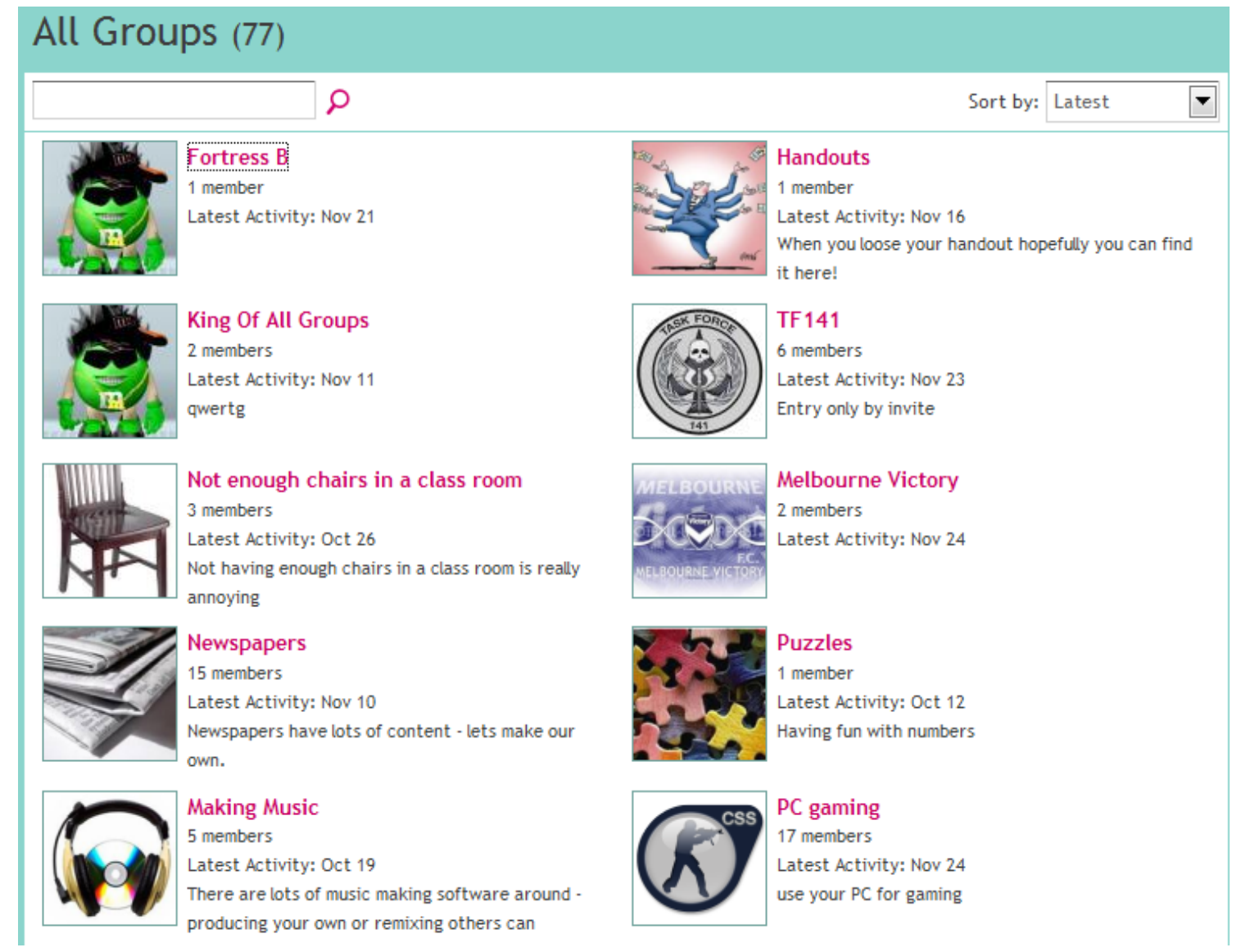

Figure 3. Screen clip showing a range of both student- and teacher-directed Ning groups.

\section{Example 2.}

It was vital for the researcher to monitor student Ning activity because the social network had to conform to the school's expectations and requirements. One morning, during the second week of using the Ning in the classroom, a feeling of confusion came over the researcher as a host of new Ning groups continued to appear. The researcher panicked and tried to change the administration settings for the network to require students to gain approval before they could start a group and be active online. She found this was not possible because she did not know how to change the setting, and due to other teaching commitments, she had no time to find out. Since very few Ning groups had appeared during the 
first week, the researcher had not predicted this eruption of groups in the second. Looking back on this occurrence, one could picture the wave as it formed, rose, broke, and crashed with an enormous splattering of particles in every possible direction. Then it calmed, and without any intervention, order returned once again. Thankfully, the teacher's instinctive response of trying to take charge and enforce order was not necessary as the chaotic Ning activity did calm down by itself. From that time on, the waves that continued to form had varying heights and points of impact, adding depth and excitement to the learning process. It was during these times that the water droplets connected and became the active drivers of their environment.

Exhausted with all the activity

Before lunchtime I had joined 12 groups trying to keep up with the student activity. I eventually tried to change the group setting to ' all groups must be approved' but I couldn't find the settings. This was on a Thursday - I have full teaching load days on Wed and Thur plus I had a meeting at the end of Thur. I didn't know how I was going to have the time to moderate everything. I would usually join their groups if I joined the group I thought the students might think twice before behaving inappropriately.

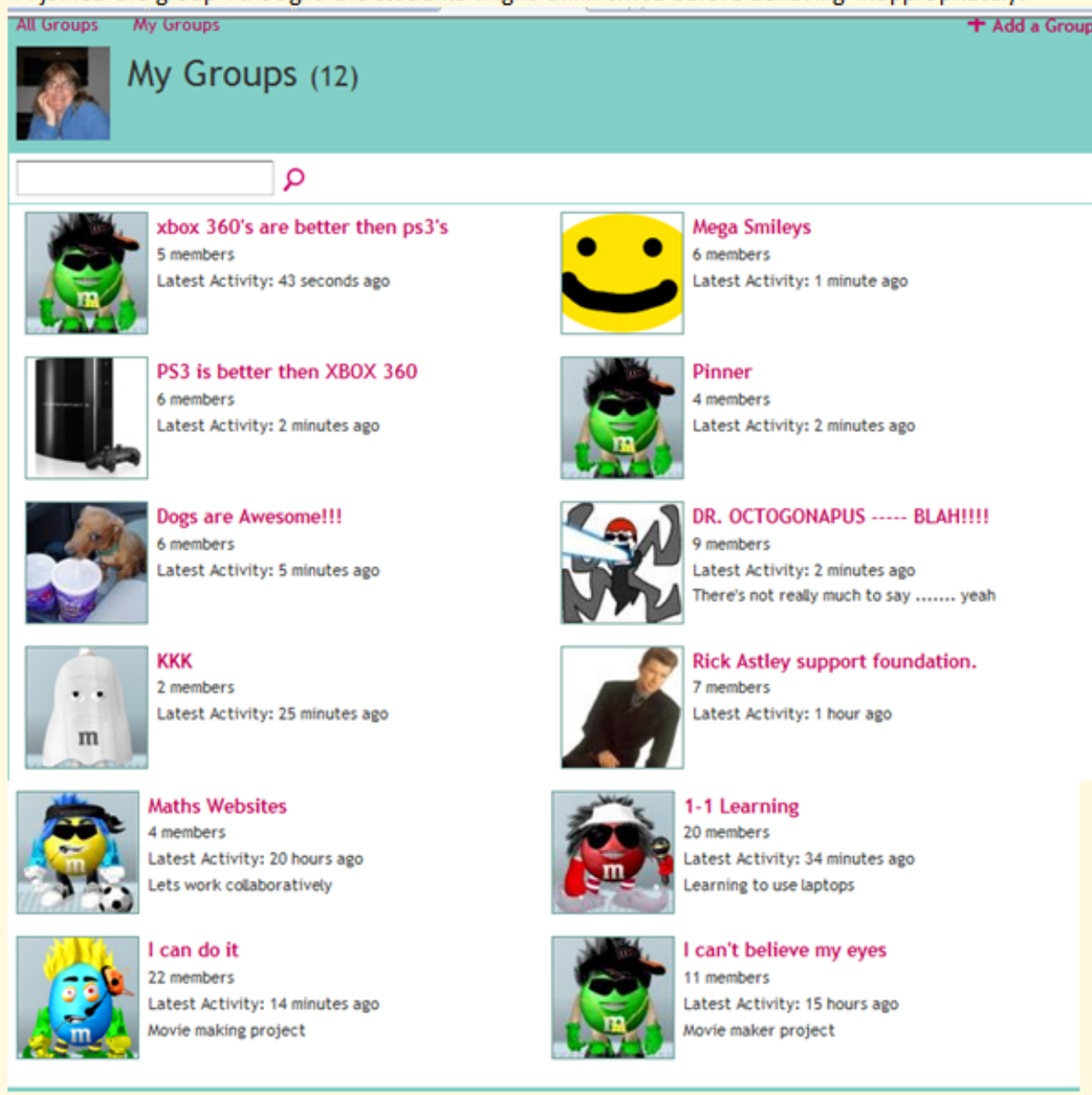

My Groups - GHS 2010

http://ghs2010,ninq, com/aroups/qroup/listForContributor? user=1 dbrtknqb6faz

Screen clipping taken: 22/07/2010, 12:02 PM

Figure 4. Sample of the researcher's comment showing that, at times, the pressure of moderating the Ning became stressful due to the unpredictability of student activity. 
The analysis of students' online interactions, combined with researcher reflections on both informal and formal learning, showed signs of developing disorder, which was significant. Using Hayles (1990) paradigm of orderly disorder, one can draw connections with some of this student-directed activity. This paradigm of disorder offers the possibility of escaping from what Hayles (1990, p. 265) describes as structures of order that are increasingly perceived as coercive. As a result, complex layering arises, where traces of old paradigms are embedded within new. On one hand we may celebrate the disorder, seeing turbulent flow not as an obstacle but as a great, swirling river of information that rescues us from sterile repetition. On the other hand it also shows that when one focuses on the underlying recursive symmetries, the deep structures that serve as foundations for chaos can be revealed and analytical solutions can sometimes be achieved (Hayles, 1990, p. 291).

\section{Example 3.}

As part of any Ning, each person automatically has access to his or her own My Page. Students could choose a theme for their page, and others could leave comments and request friendship. Figure 5 shows a student using his My Page heading to express his feelings about the loss of his pet. 


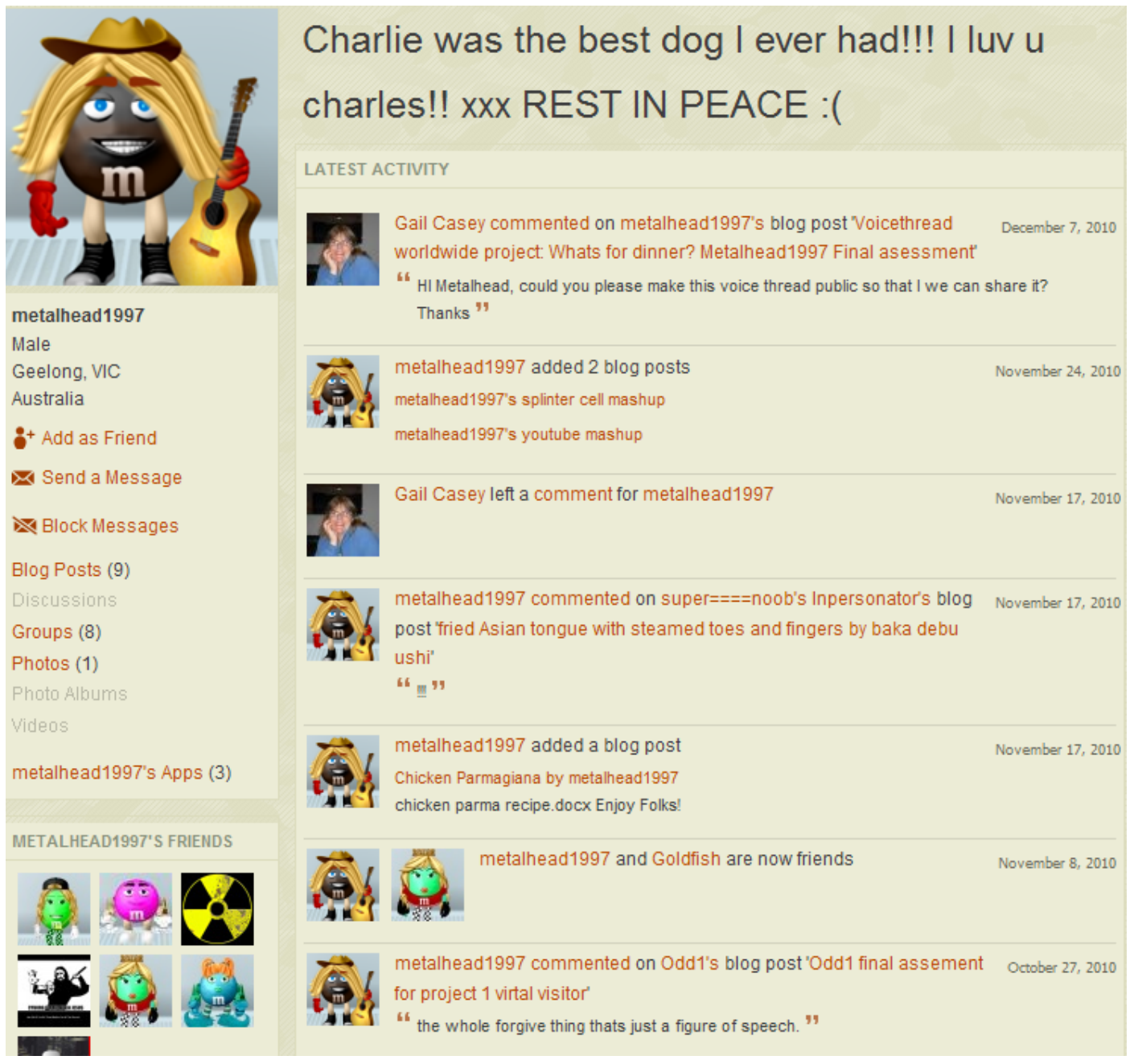

Figure 5. Screen clip of a student's My Page where he organized his theme, profile, and avatar, and published work and blogs.

Murphy's (1995, p. 28) discussion on chaos theory and education is concerned with unpredictability and indeterminism in human behavior and the implications for educational research. He states that the principles of self-renewal and self-organization are essential foundations of chaos theory, adhering to the idea of order through fluctuation. Figure 5 is one of these fluctuations: It was far from a common type of communication, and many students did not know how to respond. As a result, there was little, if any, response.

Analysis of the research data shows that the Ning was not a linear learning environment. At times it was a very dynamic system, which leads the researcher to consider Smitherman's (2005, p. 158) metaphorical interpretation of patterns in the classroom. Her perspective stems from chaos theory and lends itself to analyzing relationships that are emergent and sensitive to the system of the classroom. Sensitive dependence on initial conditions is an important component needed to generate chaotic behaviors, and small variations in conditions may lead to great differences in nonlinear dynamic systems (Smitherman, 2005, p. 160). The way students interact in the classroom is very complex; one wrong move by a student may exclude him or her from friendship groups. The researcher noted that 
circumstances were similar in the online Ning activities, so here lies a critically sensitive dependence. Smitherman's (2005) links between curriculum and chaos theories provide excellent material for thought:

Linking pedagogical goals with the unpredictable behavior of students generates a curriculum that is emergent, generative, and open. Rather than averting the "noise," a teacher can imagine "chaos" as patterns that emerge as teachable moments, embracing the notion that not everything that occurs in the classroom can be predicted. (p. 162)

Reflecting on the disorder that occurred, the researcher could see the possibilities of using disorder as a teachable moment. Understanding the implications of disorder in relation to curriculum and learning allowed her to reassess what was needed before taking control of future issues/activities. Remaining flexible and occasionally resisting teacher instinct (or perhaps the learned behavior) to take control continued to be a challenge for the researcher.

\section{Analysis: Formal and Informal Learning}

When reviewing the online data one can see the diversity of roles and activities in which the students engaged. In addition to the teacher-directed projects and the student-driven responses to these projects, much of this was evident when students were interacting with their peers at a personal level, talking about sports, games, music, and their other interests. In analyzing this type of interaction, Bertram (2002, p. 1) reminds us of when we were their age, but one key difference is the mediation of activities through electronic technologies. Students are regularly engaged with these technologies, and for many they are part of their methods of communication with friends. It was clear when looking at the broad range of student-directed groups that those who were members enjoyed and appreciated the semester-long opportunity to communicate and express themselves freely online, within school rules, as part of their classroom environment. For some students, these connections made through the Ning online social network helped them become confident and, at times, valued, yet able to remain anonymous if they so desired. The connections emphasized connectivism as an emergent theory of learning, where the interactions generated by these connections, whether informal or formal, had the potential to result in emergent knowledge.

In a classroom, a teacher may have established objectives and pedagogical goals, but in the act of instruction, he or she responds to the random interactions of the students (Smitherman, 2005, p. 160). This was also clearly evident in the Ning environment. The researcher would set out an activity and students responded in different ways, at times asking questions and eventually publishing their work. On the Ning, students had a much larger audience for their work than usual. The following screen clip shows the number of peer replies to students when working on a teacher-directed activity. In this activity, students were asked to produce a multimedia product of their choice that other students would find helpful and 
informative. Peers were then asked to give constructive feedback to one another with the aim of improving their final product. Online discussions and interactions were an important feature in providing students with constructive feedback for improvement prior to peerand self-assessment. This process of interaction was used only for major projects initially, but it gained momentum and students started to incorporate it without being asked; it appeared that students valued one another's feedback, and many enjoyed providing it. Peer feedback also improved gradually and became an important resource for both the students and the researcher. The following three screen clips show different aspects of this process: the first illustrates the number of interactions/replies different students gained when seeking feedback; the final comment on the second screen clip shows some appreciation for students who shared information; the third shows a range of individual peer assessments with feedback.

\begin{tabular}{|c|c|c|c|}
\hline \multicolumn{2}{|c|}{ Discussions } & Replies & Latest Activity \\
\hline & $\begin{array}{l}\text { betty-boo } \\
\text { how to get to the geelong high school ning } \\
\text { Started by Betty-Boo }\end{array}$ & 7 & $\begin{array}{l}\text { Sep } 16 \\
\text { Reply by JD }\end{array}$ \\
\hline & $\begin{array}{l}\text { ninja } \\
\text { 1.how to get on the program that allows you to take a screen shot and an } \\
\text { example } 2 . \text { i gonna try and learn how to use pivot cartoon animat... } \\
\text { Started by ninja. }\end{array}$ & 3 & $\begin{array}{l}\text { Sep } 16 \\
\text { Reply by mike }\end{array}$ \\
\hline & $\begin{array}{l}\text { How to use google sketch up } \\
\text { Google sketch up kyle's googel sketch up movie.swf } \\
\text { Started by Kyle }\end{array}$ & 2 & $\begin{array}{l}\text { Sep } 16 \\
\text { Reply by toby }\end{array}$ \\
\hline & $\begin{array}{l}\text { Robert } \\
\text { I am going to use SketchUp. I will be working out how to use this and all } \\
\text { the features on SketchUp. http://sketchup.google.com/http://downL... } \\
\text { Started by Robert }\end{array}$ & 11 & $\begin{array}{l}\text { Sep } 16 \\
\text { Reply by JD }\end{array}$ \\
\hline & $\begin{array}{l}\text { Toby } \\
\text { im going to use sketch up. I will be seeing what features it has } \\
\text { http://sketchup.google.com/ http://download.cnet.com/Google- } \\
\text { SketchUp/3000-... } \\
\text { Started by toby }\end{array}$ & 6 & $\begin{array}{l}\text { Sep } 16 \\
\text { Reply by Kyle }\end{array}$ \\
\hline & $\begin{array}{l}\text { klonez } \\
\text { i am doing format factory } \\
\text { Started by klonez }\end{array}$ & 9 & $\begin{array}{l}\text { Sep } 16 \\
\text { Reply by klonez }\end{array}$ \\
\hline & $\begin{array}{l}\text { JD } \\
\text { a website about paint. } \\
\text { http://www.brighthub.com/multimedia/photography/articles/2057.aspx } \\
\text { You will learn sertend tools on paint sch as the... } \\
\text { Started by JD }\end{array}$ & 2 & $\begin{array}{l}\text { Sep } 16 \\
\text { Reply by Kyle }\end{array}$ \\
\hline & $\begin{array}{l}\text { Alex's Screen Recording } \\
\text { I am doing my screen recording on OneNote. It will show how to find it, } \\
\text { basic features such as typing and how to make screen shots and save... } \\
\text { Started by Alex }\end{array}$ & 8 & $\begin{array}{l}\text { Sep } 16 \\
\text { Reply by ninja }\end{array}$ \\
\hline$m$ & $\begin{array}{l}\text { frankbob } \\
\text { im doing crocodile chemistry because i done know anything about it and } i \\
\text { dont know much about science. http://www.arborsci.com/Products_P... } \\
\text { Started by frankbob }\end{array}$ & 11 & $\begin{array}{l}\text { Sep } 16 \\
\text { Reply by mike }\end{array}$ \\
\hline
\end{tabular}

Figure 6. Screen clip showing the number of replies some students received after giving constructive feedback and support to one another.

Students' critiquing abilities continued to improve while working in the Ning, which was very encouraging. The researcher asked students to be constructive, to say something positive before giving critical feedback, and, where possible, to finish with a positive comment. 
This helped the students to build an understanding and acceptance of the opinions of others.

Comment by Kyle 19 minutes ago
Good detail in information, partiulary under 'what is animation'
Next time you may want to list some more feferences
Nice to see you've answered your own questins
thanks for the info
Comment by mouse 33 minutes ago
you have done really well and provided a lot of information! thanks for letting me borrow some, i give you a *1 $_{1}$

Figure 7. Screen clip showing student feedback and assessment, as well as appreciation from the user "mouse," who thanks another student for sharing information.

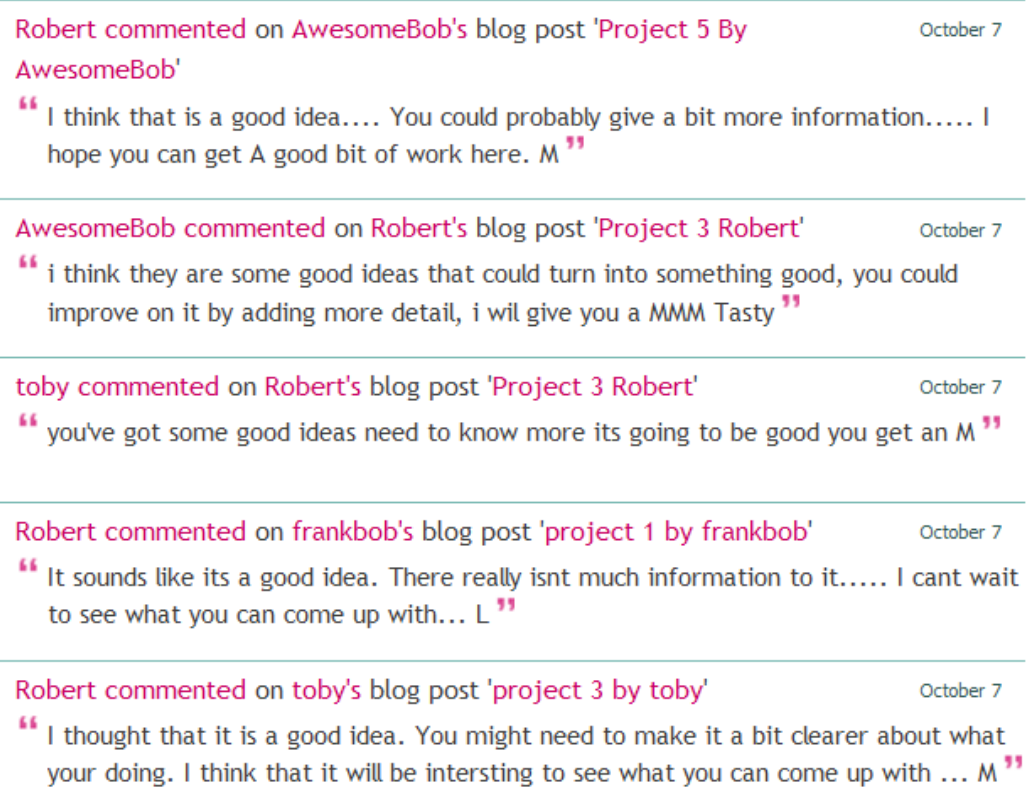

Figure 8. Examples of individual peer feedback and assessment.

When designing projects, the researcher needed to take into account the dynamics and connections the students would have in their Ning social network. Many projects allowed students to use multimedia, and they generally enjoyed and appreciated this type of interactive medium, along with interactive Web 2.0 tools. These tools encouraged students to be creative while publishing their work for the Ning's wide audience, often giving them a reason to produce higher quality work.

Students' peer feedback and assessment involved some complex interactions. The re- 
searcher continued to remind them that the process of giving feedback to others required sensitivity and the need to be constructive while being understanding and positive. When looking closely at peer feedback, one can connect it to complexity theory:

Complexity theory is an emerging field in which scientists seek patterns and relationships within systems. Rather than looking to cause and effect relations, complexity theorists seek to explicate how systems function to rely upon feedback loops (reiteration, recursion, reciprocity) so as to (re)frame themselves and thus continue to develop, progress, and emerge. (Smitherman, 2005, p. 163)

Certainly, peer feedback involved loops and recursion, and it continued to develop and progress. Smitherman (2005, p. 158) also relates classroom behavior to fractal patterns. She describes how certain patterns of behavior seem to be fixed, with some that are periodic and others that are chaotic. According to Smitherman, these fractal-like patterns display dynamic relations that occur in a class among teachers, students, subject material, and the classroom environment. Most of the Ning groups, both teacher- and student-directed, produced this fractal-like pattern of dynamic relations. One interesting example of this is shown in the following screen clip where a student formed a group in a fit of frustration. She was not listening in class, and when other students were ready to start work on a project she did not know what to do, so she asked the researcher. The researcher replied in a negative manner, knowing the student had not listened to the initial instructions. The student responded by forming a Ning group called "WHY." She deleted the group soon after it started to gain the interest of other students. 


\begin{tabular}{|c|c|}
\hline$\sum_{i=1}^{\infty}$ & $\begin{array}{l}\text { WHY } \\
\text { Posted by Odd } 1 \text { on July 28, } 2010 \text { at 11:23am in Questions with no answers } \\
\text { \& Back to Questions with no answers Discussions }\end{array}$ \\
\hline \multicolumn{2}{|c|}{$\begin{array}{l}\text { why do teachers tell us to ask questions and then critisize us for not listening??????? } \\
\text { why do best friends have stupid fights??? } \\
\text { can you really break a heart or is that just mumbo jumbo?m? } \\
\text { HELP I HAVE QUESTIONS }\end{array}$} \\
\hline+2 & $\begin{array}{l}\text { o This Discussion } \\
\text { What dificult questions you ask... } \\
\text { I think a lot of these types of problems come from frustration - especially the teacher one. Yes we do } \\
\text { want students to ask questions but we ge so frustrated when students have to ask questions because } \\
\text { they were not listening in the first place. Perhaps we get it wrong sometimes and maybe students are } \\
\text { listening but still don't understand in which case they need to ask questions. } \\
\text { Keep asking questions but not just to the teacher - I think we all have a responsibility to help each } \\
\text { other. } \\
\text { - Reply to This }\end{array}$ \\
\hline $\overrightarrow{5}$ & $\begin{array}{l}\text { Reply by metalhead1997 on August 2, } 2010 \text { at 10:04am } \\
\text { Dear Odd1, ill agree with u; These questions } r \text { hard to answer. But, } 4 \text { that break heart 1, rll say u can't } \\
\text { actually break a heart (unless you kill a person) but if u mean break up wth some } 1 \text {, the saying is just } \\
\text { another way of putting it. Like, the heart beats(!) very hard when ur in love. But when ur dumped, u } \\
\text { sort of hurt inside and people say that their heart has been broken; that means that their heart has } \\
\text { been hurt. Just something } 2 \text { think about, metalhead. } \\
\text { Reply to This }\end{array}$ \\
\hline
\end{tabular}

Figure 9. Student-directed group formed in frustration in the classroom.

When signed into the Ning, students often worked in different ways than they did when in the traditional classroom. One example of this was when students worked on projects that involved a number of different classes. The researcher established these projects to promote cross-curriculum work, and students usually found them interesting. These project work online groups gave no reference to specific classes, so most students did not know which group was related to a particular class. It was interesting to watch Year 7 students confidently connect with those in Year 10 as equals, taking on a profile of their choice.

The MashUp and Data Visualisation screen clips in Figure 10 show two shared groups that were used by the researcher to encourage students to explore interesting concepts and work across classes. 


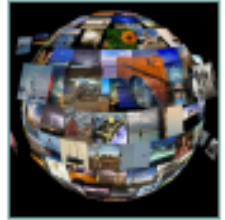

MashUps

37 members

Latest Activity: Nov. 23, 2010

Mashups, Web2

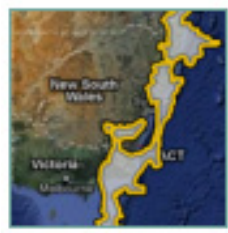

Data Visualisation

2 members

Latest Activity: Oct. 4, 2010
The MashUp group included links to a range of Web 2.0 applications. The most popular one was likely Taggalaxy (http://taggalaxy.de/), where students could look at a wide range of photos from Flickr (http://www.flickr.com/).

The Data Visualisation group was set up initially for maths, but many students from other classes looked at and discussed its contents. Students enjoyed viewing this group because it involved visual information relating to real-world events.

Figure 10. Screen clip of two teacher-directed groups. These were used for multiple classes of different ages and subjects.

Enabling students to work online allowed them to access the classroom anytime they wished. At parent-teacher interviews, parents were appreciative of the availability of online help resources and support for their children. They also acknowledged that the availability of classroom work details was useful. Having them always visible online saved the researcher time because she did not need to repeat explanations as frequently. Even so, the researcher believes that making good use of new technologies increases demands on teachers, as argued by Bertram (2002, p. 17). Through the course of this action research study, the researcher found that there was an increase in the time needed to monitor and participate in the social network. It took extra time and effort to observe the "Latest Activity" on the Ning during and after class and after school. It also took extra time to ensure that class projects, interesting Web sites, and resources were published online and available for students to access as needed. However, the researcher found that she successfully reduced her time spent on correction by implementing peer- and self-assessment with students and by using her classroom observations. This led to an effective triangulation of assessment data. The researcher felt that by making a more refined design of learning experiences for this Ning environment, she may well reach the richer and more meaningful interactions that Smitherman (2005) describes:

Chaos and complexity theories easily lend metaphorical analogies for education. There are connections within each student, but these are difficult and sometimes virtually impossible to ascertain. Instead of isolating students into one specific situation, "what is important, epistemologically and pedagogically, is a comparison of the patterns an individual develops operating in a number of different situations-this is an ecological, holistic, systematic interrelated view. Within this view lie patterns otherwise unseen" (Doll, 1993, 92). These patterns allow students not to suspend part of who they 
are in order to participate but rather encourage the development of oneself, and thus produce even richer and more meaningful interactions. (p. 177)

\section{Conclusion}

\section{Connecting the Dots ...}

As the authors continue to analyse and review this research we think of the connectthe-dot puzzles enjoyed by children. In the minds of parents there was only one correct answer, but in a child's mind there were endless playful pictures that could be formed. We look forward to finding new and novel ways to examine the data from this study through the different perspectives of theorists. As educators interested in innovative approaches to teaching, the idea of designing learning activities that take account of emergence and connections is encouraging. This is especially the case when teaching young people who are experienced social beings, both online and face-to-face. Connections to fractal patterns and chaos theory are very real in the online classroom, where interaction can be used as a vehicle for learning, and students' awareness of their own communications encourages them to be active participants in the learning process. This research supports Smitherman's theory (2005, p. 168) that learning occurs in nonlinear patterns: emergent, divergent, and convergent.

Imagine the impact on classroom teaching, tutoring, and educational research if it were recognized that linearity has often been falsely assumed in teaching and learning (Kahn, 2005, p. 181). It was clear in this study that participants were able to take control of many aspects of learning, including supporting and assessing their peers. Their online connections served a purpose, diversifying their networks and uncovering new possibilities for learning. In many ways, these students' interactions supported the communities of practice model used in professional learning for teachers, as discussed by Mackey and Evans (2011). One can imagine both teachers and students learning together online, with the students acting as facilitators. It was clear in this study and that of Mackey and Evans that participants took control of their online learning experiences; perhaps the problem is that, too often, educators do not offer to hand over this control. That is why the words of Doll, who encourages the future of active and emergent learning, are crucial:

A dynamic, emergent curriculum, transformative in its processes, sees both the learner and the curriculum (child and curriculum, in Dewey's phrasing) having their own voice. The point-counterpoint of this duet/dialogue, with practice and over time, produces transformative results. . . . In this way, child and curriculum, learner and teacher, self and text, person and culture, dance together to form a complex pattern-ever changing, ever stable, ever alive.

(Doll, 2005b, p. 55) 
Such a redesign of learning requires both teachers and students to be learners, working together in nonlinear ways. Teachers cannot take this approach in fear of chaos and disorder; they must find innovative ways to construct disorder and flow with chaos and build resilience to the traditional training that instinctively drives them to take control. Doll (1993, p. 16) asserts that we must all begin where we are. This gives educators their entrée into postmodern curriculum practice, where they individually develop their own pedagogic practicalities for curriculum. For the authors, with different, but related, interests in chaos and complexity theories, there are creative possibilities. With this in mind, one must also consider the words of Klaus (2010):

It is an established fact that the vast majority of systems or processes in the real world are so complicated that there is no hope and even no sense in trying to analyze them in full detail. The method of analysis for social sciences and in the humanities involves observation and thought along with creating notions and their operational interactions. The very process of modelling even a small part of reality is naturally accompanied by a loss of information, in the sense that some aspects are deliberately eliminated from further considerations. (p. 18)

So the question that should now be asked while reviewing this research data comes from Doll: "has the teacher, intentionally or otherwise, caused enough chaos to motivate her students to reorganise? Too much chaos will lead to disruption, while too little chaos will produce no reorganization" (Doll, 1987, p. 16).

\section{Acknowledgement}

We wish to acknowledge David Whelan, principal of Geelong High School, for his support and encouragement for Gail Casey's PhD project. 


\section{References}

Alvarez, M. C. (Ed.). (2001). Developing critical and imaginative thinking within electronic literacy. Newark, DE: International Reading Association.

Armstrong, F., \& Moore, M. (2004). Action research: Developing inclusive practice and transforming cultures. In F. Armstrong \& M. Moore (Eds.), Action research for inclusive education: Changing places, changing practice, changing minds (pp. 1-16). London: Routledge.

Atkinson, T., \& Claxton, G. (2000). Introduction. In T. Atkinson \& G. Claxton (Eds.), The intuitive practitioner: On the value of not always knowing what one is doing (pp. 1-12). Buckingham, England: Philadelphia Open University Press.

Beane, J. A. (2006). A middle years curriculum: From rhetoric to reality (3rd ed.). Heatherton, Australia: Hawker Brownlow Education.

Bertram, B. C. (2002). Diversity and critical social engagement: How changing technologies enable new modes of literacy in changing circumstances. In D. E. Alvermann (Ed.), Adolescents and literacies in a digital world (pp. 1-18). New York: P. Lang.

Brophy, J. (2006). Graham Nuthall and social constructivist teaching: Research-based cautions and qualificaitons. Teaching and Teacher Education 22(5), 529-537.

Brown, J. S. (2002). Growing up digital: How the Web changes work, education, and the ways people learn. Retrieved from http://www.elearnspace.org/Articles/networks.htm

Claxton, G. (2000). The anatomy of intuition. In T. Atkinson \& G. Claxton (Eds.), The intuitive practitioner: On the value of not always knowing what one is doing (pp. 32-52). Buckingham, England: Philadelphia Open University Press.

Dillon, N. (2006). Skills for a new century. American School Board Journal, 193(3), 22-26.

Doll, W. E. (1987). Prigogine: A new sense of order, a new curriculum. Theory Into Practice, 25(1), 10-16.

Doll, W. E. (1993). A post-modern perspective on curriculum. New York: Teachers College Press.

Doll, W. E. (2005a). Chaos and complexity theories. In W. E. Doll, M. J. Fleener, \& J. St. Julien (Eds.), Chaos, complexity, curriculum and culture: A conversation. (pp.117). New York: P. Lang.

Doll, W. E. (2005b). The culture of method. In W. E. Doll, M. J. Fleener, \& J. St. Julien (Eds.), Chaos, complexity, curriculum and culture: A conversation (pp. 21-75). New York: P. Lang. 
Draut, M. (2000). The intuitive practitioner: A critical overview. In T. Atkinson \& G. Claxton (Eds.), The intuitive practitioner: On the value of not always knowing what one is doing (pp. 155-168). Buckingham, England: Philadelphia Open University Press.

Edmonds, K. (2006). Using digital imagery in learning: A new literacy. Paper presented at the International Conference of the Society for Information Technology and Teacher Education, Orlando, FL.

Fleener, J. (2005). Introduction: Chaos, complexity, curriculum and culture. In W. E. Doll, M. J. Fleener, \& J. St. Julien (Eds.), Chaos, complexity, curriculum and culture: A conversation (pp. 2-17). New York: P. Lang.

Fletcher, G. H. (2007). Bloggers welcome here: Social networking tools appear poised to enter the school system. It's a breakthrough long overdue. T H E Journal (Technological Horizons in Education), 34(11), 8.

Glover, I., \& Oliver, A. (2008). Hybridisation of social networking and learning environments. Paper presented at the World Conference on Educational Multimedia, Hypermedia and Telecommunications, Vienna, Austria.

Hahn, J. (2008). Born digital: Understanding the first generation of digital natives. Library Journal, 133(13), 105.

Hayles, N. K. (1990). Chaos bound: Orderly disorder in contemporary literature and science. Ithaca, NY: Cornell University Press.

Johnson, D., \& Kress, G. (2003). Globalisation, literacy and society: Redesigning pedagogy and assessment. Assessment in Education: Principles, Policy \& Practice, 1O(1), 5.

Kahn, R. (2005). Prospects for Nonlinear Education-Reflections from Lord (Robert) May. In W. E. Doll, M. J. Fleener, \& J. St. Julien (Eds.), Chaos, complexity, curriculum and culture: A conversation (pp. 182-191). New York: P. Lang.

Klaus, L. (2010). Emergence, analysis and evolution of structures: Concepts and strategies across disciplines. Heidelberg: Springer.

Luke, A., \& Elkins, J. (2002). Towards a critical, worldly literacy. Journal of Adolescent \& Adult Literacy, 45(18), 668-674. Retrieved from http://search.ebscohost.com/ $\underline{\text { login } . \text { aspx }}$ ?direct $=$ true $\& d b=a p h \& A N=6629784 \&$ site $=$ ehost-live

Mackey, J., \& Evans, T. (2011). Interconnecting networks of practice for professional learning. International Review of Research in Open and Distance Learning, 12(3), 1-17. 
Mason, R. (2008). E-learning and social networking handbook: Resources for higher education. New York: Routledge.

Merchant, G. (2007). New literacies: Everyday practices and classroom learning (2nd ed.) [Review of the book by Colin Lankshear \& Michele Knobel]. Literacy, 41(3), 177179.

Murphy, D. G. (1995). Chaos rules: An exploration of the work of instructional designers in distance education (Doctoral thesis). Deakin University, Geelong, Australia.

Nuthall, G. (2002). Social constructivist teaching and the shaping of students' knowledge and thinking. In J. Brophy (Ed.), Social constructivist teaching: Affordances and constraints (pp. 43-79). New York: Elsevier.

Nuthall, G. (2007). The hidden lives of learners. Wellington, NZ: New Zealand Council for Educational Research.

Pickover, C. A. (1996). Fractal horizons: The future use of fractals (1st ed.). New York: St. Martin's Press.

Prensky, M. (2010). Teaching digital natives: Partnering for real learning. Thousand Oaks, CA: Corwin Press.

Reamsbottom, B., \& Toth, C. (2008). The mash-up of Web 2.o technologies: The future of podcasting and social networking. Paper presented at the International Conference of the Society for Information Technology and Teacher Education, Las Vegas, Nevada.

Smitherman, S. (2005). Chaos and complexity theories. In W. E. Doll, M. J. Fleener, \& J. St. Julien (Eds.), Chaos, complexity, curriculum and culture: A conversation (pp. 153-180). New York: P. Lang.

Sultan, N. (2010). Cloud computing for education: A new dawn? International Journal of Information Management, 3o(2), 109-116.

Szempli, W., \& Stupnicka, S. (2003). Chaos, bifurcations and fractals around us: A brief introduction. Singapore: World Scientific Publishing Company.

Weinberger, D. (2008). Digital natives, immigrants and others. KM World, 17(1), 1-24.

Wells, M. (2007). Wikis, blogs and podcasts-Using Web2 technologies in teacher education. Retrieved from http://www.aare.edu.au/o7pap/welo7108.pdf

Wheeler, S. (2001). Information and communication technologies and the changing role of the teacher. Learning, Media and Technology, 26(1), 7-17.

Williams, B. T. (2008). Tomorrow will not be like today: Literacy and identity in a world of 
multiliteracies. Journal of Adolescent \& Adult Literacy, 51(8), 682.

Yuen, S. C.-Y., \& Yuen, P. (2008). Web 2.o in education. Paper presented at the International Conference of the Society for Information Technology and Teacher Education, Las Vegas, Nevada.

\section{Athabasca University $\mathbf{I}$}

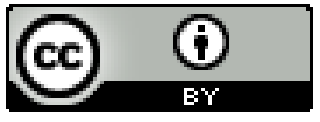

